\title{
A Linguagem como médium entre a materialidade e a idéia
}

\author{
Gustavo Arantes Camargo
}

RESUMO: A partir de uma abordagem ampla da linguagem, Benjamim desenvolve uma compreensão desta que vai além da fala e da escrita. As próprias coisas comunicam-se ao homem e este, a partir de sua própria linguagem, comunica-as a Deus. O caráter teológico fortemente marcado em Benjamim aponta a necessidade de salvação da história. Salvação esta que deve ser empreendida na linguagem. Esta se torna, assim, um médium capaz de apresentar a verdade. O papel da filosofia não seria o do conhecimento, mas sim o de apresentar a verdade. A linguagem eterniza o momento. Acontecendo assim com a história, sendo esta a redenção de um passado catastrófico que é esquecido em uma temporalidade homogênea que visa o progresso. A linguagem é, portanto, capaz de apresentar a verdade existente na própria materialidade das coisas que, por sua vez, comunicam sua essência espiritual ao homem. Essa seria sua potência messiânica de salvação e cura.

Palavras-chave: Benjamin, Linguagem, Verdade, Origem e História.

ABSTRACT: From an ample approach to the task of language, Benjamin produces and comprehension that goes far beyond speech and write. The proper things communicate themselves to man and him, from his language, communicate them to God. The strong theological character point us to a necessity of save the historical phenomenon. This salvation is the language's task. Language assumes a role of medium able to present truth. This role will be played in the study of history, where is needed to rewrite the facts, being able to escape from a homogeneous way of thinking time.

Key-words: Benjamin, Language, Truth, Origin and History.

* Gustavo Arantes Camargo é Doutor em Filosofia pela PUC-Rio. Professor Substituto do Departamento de Educação da UERJ (Faculdade de Formação de Professores-FFP) 


\section{A Linguagem como médium entre a materialidade e a ideia}

\section{Uma Compreensão Ampliada da Linguagem}

Em seu texto de 1916, intitulado "Sobre a linguagem em geral e sobre a linguagem humana", Walter Benjamin expõe uma compreensão de linguagem que vai além da fala e da escrita. Ele expõe a teoria de uma linguagem geral que abrange também os seres da natureza e os objetos, a todos os seres animados e inanimados. Dentro desta compreensão, tudo possui uma linguagem; tudo se apresenta em uma forma que não se dissocia do conteúdo. Esta forma é a sua linguagem. A linguagem se estende a tudo, sendo a linguagem humana da palavra apenas um caso particular. A linguagem aparece entendida então, como toda e qualquer forma de comunicação de conteúdo, seja ele intelectual ou espiritual.

Esta compreensão de que tudo tem uma linguagem decorre da proposta de que cada coisa tem um conteúdo espiritual a ser comunicado. Este conteúdo espiritual, presente até mesmo nos objetos, como em um candeeiro, se comunica na linguagem. A linguagem é a forma na qual se comunica este conteúdo espiritual. Por isto, o conteúdo não se comunica através da linguagem, mas na linguagem. Dentro desta exposição, forma e conteúdo são indissociáveis. Isto não quer dizer que o conteúdo espiritual seja igual à linguagem. Benjamin usa a alegoria das meias, onde encontramos as meias enroladas em forma de bola, mas ao desenrolá-las, encontramos exatamente as meias. As meias são meias, seja em forma de bola seja em forma de pé. O conteúdo espiritual da meia se comunica em sua linguagem-bola ou em sua linguagem-pé. Quando a expressão de algo é a comunicação de seu conteúdo espiritual, isto é a linguagem.

De fato, é uma evidência plena de conteúdo a afirmação de que nada podemos imaginar que não comunique a sua essência espiritual, manifestando-a na expressão... ${ }^{1}$

É importante diferenciarmos aqui a linguagem daquilo que nela se expressa. Aquilo de que a linguagem é expressão é a essência espiritual e não a própria linguagem. O que se expressa na linguagem, este "se", é a essência espiritual, diferenciada, portanto, daquilo que

\footnotetext{
${ }^{1}$ Benjamin. "Sobre a linguagem em geral e sobre a linguagem humana”, pág. 178.
} 
a comunica, que é a essência lingüística. A essência espiritual não está na linguagem, mas se comunica nela. Esta diferenciação é muito importante. A filosofia corre um sério risco ao identificar, logo como hipótese, a essência lingüística e a essência espiritual.

A essência espiritual é idêntica à lingüística só "na medida em que é comunicável". O comunicável numa essência espiritual é sua essência lingüística. ${ }^{2}$

Existe então, uma essência espiritual não-comunicável que se diferencia da linguagem. Desta forma, a linguagem comunica a si mesma ao comunicar o que é comunicável em uma essência espiritual, que é a essência lingüística. "Aquilo que numa essência espiritual é comunicável é a sua linguagem"3. A essência se expressa imediatamente na linguagem, mas essência e linguagem não são a mesma coisa. O que se comunica em uma coisa é a coisalinguagem, não a coisa toda. A linguagem é assim, o médium da comunicação. Mas não um médium através do qual algo é comunicado, e sim o lugar onde algo se comunica imediatamente a si mesmo. Este imediatismo é, para Benjamin, a principal questão da teoria da linguagem e chega a chamá-lo de mágico. Até aqui está se falando da linguagem em geral, mas a linguagem do homem, quando pensada dentro desta abordagem, ganha também uma nova dimensão.

O homem comunica sua própria essência espiritual $n a$ sua linguagem. Mas a linguagem do homem fala por palavras. O homem comunica, pois, a sua própria essência espiritual (na medida em que é comunicável) denominando todas as outras coisas ${ }^{4}$.

A linguagem na qual o homem comunica sua essência espiritual é uma linguagem designadora e, por ser a única linguagem designadora que conhecemos, ela se torna interessante ao ser capaz de permitir que a essência espiritual se comunique em palavras. Porém, caso se incorra no erro de fazer desta linguagem designadora a linguagem em geral, perde-se a possibilidade de uma "compreensão mais profunda e íntima das coisas". 5 A essência espiritual do homem se comunica denominando as coisas. Benjamin diz que esta

\footnotetext{
${ }^{2}$ Ibid. p. 179.

${ }^{3}$ Ibid. p. 179.

${ }^{4}$ Benjamin, "Sobre a linguagem em geral e sobre a linguagem humana", p. 180

${ }^{5}$ Ibidem, p. 180
} 
capacidade de denominá-las se dá devido ao fato de as coisas se comunicarem ao homem. $\mathrm{O}$ homem se comunica denominando as coisas porque as coisas se comunicam a ele. $\mathrm{O}$ homem comunica sua essência espiritual no nome que dá às coisas.

Mas a quem se comunica o homem? A resposta não poderia ser mais característica deste filosofo. Contra uma compreensão burguesa da linguagem, onde esta é vista de forma utilitária, na qual o homem comunica através de palavras um objeto a outro homem, Benjamim introduz a dimensão teológica que acompanha seu pensamento. "No nome, a essência espiritual do homem transmite-se a Deus"6. Aqui aparece a grande importância da linguagem humana que, ao nomear as coisas, adquire um significado altamente elevado. $\mathrm{O}$ nome "é a essência mais íntima da própria linguagem"”. "O nome é aquilo (...) no qual a própria linguagem se comunica, em absoluto" ${ }^{\text {. }}$ O nome comunica a própria linguagem. Sendo o nome a linguagem do homem, a essência espiritual do homem é a única totalmente comunicável. A expressão daquilo que é mais espiritual torna-se possível na linguagem do nome, chegando assim ao conceito de revelação. A linguagem da matéria é menos completa que a linguagem do nome. Esta última é puramente espiritual e por isto é tão importante. O potencial messiânico de revelação e redenção está contido na linguagem do nome e, por isto, ela é tão importante para Benjamim. Veremos agora, como este nome pode chegar à verdade.

\section{Linguagem e Verdade: Uma Crítica do Conhecimento}

A linguagem é capaz de comunicar uma essência. Esta essência não se comunica através da linguagem, mas na linguagem. A linguagem apresenta esta essência. Esta compreensão fica mais clara quando Benjamin coloca como principal questão da filosofia a questão da apresentação da verdade. A verdade possui uma dimensão sensível, ela não se separa da sua apresentação. A linguagem apresenta a verdade, pois esta se encontra naquela no momento de sua aparição, ainda que seja apenas por um instante tão rápido como um relâmpago. Não se trata de representar com símbolos a verdade, pois neste caso a verdade estaria ausente, seria possível, no máximo, representá-la e não apresentá-la. O conceito que Benjamim usa é

\footnotetext{
${ }^{6}$ Ibidem, p. 181

${ }^{7}$ Ibidem, p. 181

${ }^{8}$ Ibidem, p. 181
} 
Darstellung que, como ressaltou Jeanne-Marie Gangnebin ${ }^{9}$, deve ser traduzido por apresentação e não por representação, para evitar a associação da filosofia da linguagem de Benjamim com a filosofia clássica da representação.

Neste contexto, a verdade não seria tampouco dedutível pela forma de um sistema perfeito, ao contrário, a filosofia, ao buscar a verdade, deve abandonar a forma de sistema se quiser atender àquilo que se propõe. A verdade, para Benjamin, não é capturável sob a forma de conhecimento. O conhecimento lida com um objeto externo a ele, busca apreender cada vez mais informações sobre este objeto. Já a filosofia, com o uso da reflexão, volta-se para dentro de si mesma e buscará apresentar aí a verdade. A verdade foge a qualquer tipo de posse, e saber é posse, por isto não é possível chegar até ela pelo conhecimento. A forma de apresentação da verdade não pré-existe como um sistema, ela é dada juntamente com a verdade. Não existe método direto para se chegar à verdade.

Para dar conta de sua tarefa, a filosofia deve atentar para a forma. Esta, como foi visto, não é dissociável do conteúdo. Se a filosofia se propõe ter como conteúdo a apresentação da verdade, então a forma como esta verdade se apresenta é fundamental para o sucesso de sua empreitada. O tratado filosófico ou o ensaio são as formas onde melhor se apresenta a verdade. Esta se mostra inapreensível pelo rigor matemático que termina apenas por limitar coercitivamente o pensamento. Não é um sistema fechado que será capaz de chegar à totalidade da verdade, mas justamente os fragmentos pormenorizados do pensamento é que compõem, como num mosaico, uma possível totalidade. Uma totalidade que se encontra já em cada fragmento e não em uma dedução ou intuição lógica.

A unidade do saber, se é que ela existe, consiste apenas numa coerência mediata, produzida pelos conhecimentos parciais e de certa forma por seu equilíbrio, ao passo que na essência da verdade a unidade é uma determinação direta e imediata. ${ }^{10}$

A verdade é total e una, sem perder a singularidade, por isto é uma mônada. A apresentação de que Benjamin fala é a apresentação das ideias. As ideias são o objeto da investigação

\footnotetext{
${ }^{9}$ Gagnebin, "Do conceito de Darstellung em Walter Benjamim ou verdade e beleza”, revista Kriterion, vol 46, no. 112.

Endereço eletrônico: http://www.scielo.br/scielo.php?script=sci_arttext\&pid=S0100-512X2005000200004

${ }^{10}$ Benjamin, "Questões introdutórias da crítica do conhecimento", p. 52
} 
filosófica. "A distinção entre a verdade e a coerência do saber define a ideia como Ser"11. Desta forma, a verdade está ligada às ideias e não ao conhecimento. Por isto, se a filosofia pretende ser a apresentação da verdade ela deve ser também a apresentação das idéias, apresentação que se dá na linguagem, fugindo da relação sujeito-objeto, que caracteriza o saber representacional.

\section{A Historicidade do Eterno: A Salvação dos Fenômenos}

A questão parece ser também a de como apresentar a verdade em sua unidade, mas preservando sua singularidade. Longe de um conceito que identifique o não idêntico, que despreze as diferenças em nome de uma unidade inexistente, a dificuldade é, justamente, entender como algo singular pode trazer em si algum tipo de unidade, que é inerente à verdade. Aqui aparece de novo a grande importância da linguagem humana para a apresentação da verdade, ou da essência. Os elementos materiais não entram em contado direto com a ideia. A salvação do fenômeno ou da obra de arte se dá quando eles se veem incendiados e decompostos em seus elementos e somente estes se salvam. "Nessa divisão, os fenômenos se subordinam aos conceitos. São eles que dissolvem as coisas em seus elementos constitutivos" ${ }^{2}$. A linguagem como médium permite aos fenômenos participarem do mundo das ideias, salvando-os. A salvação do fenômeno se dá justamente quando ele escapa do caráter passageiro do tempo e salta para fora dele, salvando-se e se redimindo no mundo das ideias. $\mathrm{O}$ conceito proporciona a redenção do fenômeno. Este mesmo caráter mediador da linguagem permite a apresentação das ideias. A verdade se apresenta empiricamente no conceito, que então faz o caminho inverso do feito pelo fenômeno e apresenta a ideia em sua dimensão sensível. "A redenção dos fenômenos por

\footnotetext{
${ }^{11}$ Ibidem, p. 52

${ }^{12}$ Benjamin, "Questões introdutórias da críticado conhecimento", pág 56
} 
meio das ideias se efetua ao mesmo tempo em que a apresentação das ideias por meio da empiria" $" 13$.

Desta forma há um encontro entre duas temporalidades. A temporalidade eterna da ideia que encontra sua historicidade ao apresentar-se no conceito, e a historicidade do fenômeno que encontra sua eternização redentora no mundo das ideias com o conceito. Mas os fenômenos não estão nas ideias. Estas são eternas e, portanto, anteriores àqueles. O que acontece é a ordenação dos fenômenos no campo das ideias. Ao serem salvos, os fenômenos se inscrevem em uma ordenação dada pelas ideias que os interpretam objetivamente. As ideias constroem uma constelação com os fenômenos, mas os fenômenos não são as ideias e vice-versa. Ao salvar uma coisa de sua perdição na história, o conceito relaciona os fragmentos desta coisa com a ideia, tornando-os eternos e, ao mesmo tempo, atualizando a ideia. Ao atualizar a ideia que salva a experiência empírica, o conceito deve conseguir também apresentar a verdade da ideia. Esta dupla tarefa é a tarefa do conceito, da linguagem. Aqui a linguagem aparece com sua grande importância para Benjamin, ela é responsável não só por apresentar a verdade e a ideia, como também por salvar os fenômenos do esquecimento, escrevendo sua história. História e linguagem se articulam na dimensão teológica da redenção.

A pedra de toque desta linguagem redentora da experiência empírica e apresentadora da verdade e das ideias é o nome. Este é o modo de ser das ideias, sua forma de apresentar-se; a ideia apresenta-se no nome, a linguagem do homem como nomeadora do mundo. Benjamin evoca aqui uma linguagem original, que chama de adâmica, onde ao nomear já se apresentava imediatamente a verdade. A perda desta linguagem está ligada à queda do paraíso. Depois do pecado original, o homem se viu em uma Babel de línguas, sendo tarefa da filosofia agora, traduzir na língua do homem moderno aquela verdade perdida da língua adâmica. Se a linguagem pudesse recuperar sua dimensão expressiva, retornaríamos ao paraíso. Mas isto não é possível, nossa linguagem desgastada se permite apenas uma "frágil força messiânica" ${ }^{\prime 14}$. Entretanto, esta frágil força messiânica conserva uma centelha, uma dimensão, ainda que sutil, daquele caráter expressivo original, e nisto reside a importância da linguagem, que ainda é capaz de apresentar a ideia. Tentar rememorar a expressividade

\footnotetext{
${ }^{13}$ Ibidem, p. 56 (tradução modificada)

${ }^{14}$ Benjamin, "Sobre o conceito de história", tese 2
} 
da linguagem adâmica significa aproximar a filosofia da questão do ser. Na linguagem adâmica o nome não se diferencia do ser. Trata-se de encontrar na linguagem cotidiana a dimensão adâmica que ainda persiste e assim, apresentar o ser.

Se o nome é o modo pelo qual se apresentam as ideias, a linguagem do texto filosófico pode apresentar a verdade. A linguagem que não mais convence com argumentos excessivos que detém o conhecimento certo, mas a linguagem que experimenta formas alegóricas de apresentar a verdade em imagens, imagens literárias que apresentem melhor do que qualquer argumentação a ideia que se esconde naqueles nomes. O caráter imagético da ideia aparece no nome. O ser da ideia aparece no nome. A verdade se diferencia do conhecimento também, pois pode sempre ser renomeada. A verdade aparece justamente nas múltiplas explicações para uma alegoria e não em um sentido único e certo para o conhecimento. A multiplicidade de sentidos dissolve simultaneamente o sujeito e o objeto do conhecimento na medida em que é somente depois de dissolvido em conceitos que o fenômeno passa a integrar a constelação das idéias; a verdade destas ideias aparece como construção. $\mathrm{O}$ fato da ideia e da verdade poderem sempre ser renomeadas e atualizadas faz com que, apesar de eternas, elas não estejam de maneira nenhuma paradas. A questão passa a ser então: qual é o ser do vir-a-ser?

A ideia é um eterno vir-a-ser e está diretamente relacionada com a história a ponto de podermos afirmar a historicidade de algo eterno. A experiência empírica é importante, mas na medida em que só é salva pelo nome, é também uma construção. Esta construção, como já foi dito, não evoca um sujeito consciente que nomeia e explica o empírico. $O$ pesquisador constrói o fato, constrói interpretações do mundo, mas é o mundo real que revela uma interpretação. Não é a subjetividade do pesquisador que a cria. O mundo real se apresenta como tarefa, pois estamos nele mergulhados, ele se apresenta à interpretação. As coisas se apresentam à contemplação filosófica e esta é capaz de interpretá-las e apresentar uma verdade. Mas a imersão na materialidade do empírico é fundamental para esta tarefa, pois é aí que se apresentam as ideias. É na imersão total nos pormenores do empírico que é possível se chegar a uma ideia. É no fragmento que se encontra o todo. O todo não é um somatório de fragmentos. "Pois é o minúsculo que a reflexão encontrará a sua frente, sempre que mergulhar na obra e na forma de arte para avaliar seu conteúdo" ${ }^{\text {"15 }}$. A salvação

\footnotetext{
${ }^{15}$ Benjamin, "Questões introdutórias da crítica do conhecimento", p. 67
} 
do fenômeno se dá portanto, na imersão em seus pormenores. Esta é uma característica da ideia como mônada.

Aqui se introduz um conceito fundamental para a compreensão de linguagem, salvação e história em Benjamin que é o de origem. A origem é uma categoria histórica, mas diferencia-se totalmente da gênese. A origem não é o momento do surgimento de algo, mas seu encontro com a verdade no reino das ideias. $\mathrm{O}$ instante fugaz em que o acontecimento histórico é renomeado e se salva é o que determina sua origem. A salvação do acontecimento como ideia instaura sua origem. É um momento de temporalidade intensiva que rompe com a cadeia cronológica do tempo e possibilita uma certa parada no tempo. $\mathrm{O}$ acontecimento pára o tempo ao tocar a ideia. Como já vimos, só poderá tocar a ideia ao ser decomposto em conceitos que sejam capazes de apresentá-lo como verdade, eternizá-lo. O acontecimento tornado verdade ao ser decomposto em conceitos, a verdade apresentando-se no acontecimento que tem aí sua origem, assim a linguagem se articula de maneira inseparável com a história. Agora se compreende a necessidade de se fazer história. Mas não qualquer história e sim uma história materialista, que mergulha na materialidade e aí encontra a verdade parando o tempo e instaurando a origem do acontecimento. Esta nova temporalidade rompe com uma explicação causal dos acontecimentos históricos e propõe a busca de sua explicação não fora dele, mas em seus detalhes.

Mais uma vez o conceito de mônada, tomado de Leibniz, aparece aqui para caracterizar ainda melhor a ideia e fortalecer a proposta histórica de Benjamin. Tanto a obra de arte quanto o acontecimento histórico não podem ser explicados por elementos exteriores a eles e que os inclua em uma história da arte ou em um tempo homogêneo e vazio. Já na epígrafe do prefácio de sua tese de livre docência, Benjamin expõe o caráter monadológico que quer ampliar inclusive para a ciência, pois quem sabe assim, ela se torna capaz de atingir a verdade. Esta epígrafe mostra a dificuldade de se chegar a alguma compreensão do todo e aponta a ciência como incapaz de atingir tal objetivo, pois busca este todo na soma das partes. Longe deste somatório, o todo aparece sempre em cada acontecimento particular, assim como em cada obra individual. A teoria da linguagem de Benjamim se aplica tanto aos fenômenos históricos quanto às obras de arte. Cada obra de arte se apresenta como singular e única, mas isto não nos impede de classificarmos tanto um quadro quanto uma música de obras primas. A obra de arte é uma mônada, pois cada obra de arte, por mais 
singular que seja, traz consigo uma totalidade que nos permite chamá-la de arte, ao mesmo tempo, uma obra de arte não precisa ser igual a outra para poder ser chamada de obra de arte, ou seja, ela mantém sua singularidade. A mesma coisa acontece com os fatos históricos. Eles guardam em suas minúcias a chave que permite ao historiador ou ao filósofo estudá-lo e salvá-lo. É ao desvendar seus pormenores que se torna possível a intelecção da totalidade. Pois é a partir da decomposição dos pormenores que o fato ou a obra de arte tornam-se passíveis de serem salvos. É na descrição dos pequenos acontecimentos que a verdade sobre um todo pode aparecer. A estrutura de mônada permite tanto à arte quanto à história manterem sua singularidade sem que caiam em estruturas que lhes são exteriores. Cabe à linguagem, como sempre, ser o médium entre a arte e a história, de um lado, e as ideias e a verdade, de outro.

\section{O Caráter Messiânico da História: Por Uma Outra Temporalidade}

O conceito de origem aparece como forma de se pensar uma outra temporalidade para a história; a origem é o momento de contato entre a história e a ideia. Desta forma salva-se eternamente na ideia o fato histórico passageiro. O historiador aparece como colecionador que estuda cada acontecimento como uma peça singular de sua coleção e não como alguém que estabelece relações de causa e afeito entre os acontecimentos. Aqui o fato histórico não é encadeado em uma seqüência explicativa que lhe é exterior. Esta forma de apresentação salva o fenômeno do esquecimento que a historiografia causal promove ao dar-lhe uma explicação já pronta. A origem é capaz de dar outra temporalidade ao estudo da história.

O Ursprung designa, portanto, a origem como salto (Sprung) para fora da sucessão cronológica niveladora à qual uma certa forma de explicação histórica nos acostumou. Pelo seu surgir, a origem quebra a linha do tempo, opera cortes no discurso ronronante e nivelador da historiografia tradicional. $^{16}$

A origem é capaz de instaurar uma quebra no tempo. A temporalidade aqui, não é a temporalidade homogênea de um tempo infinito, a temporalidade está no objeto de estudo,

\footnotetext{
${ }^{16}$ Gagnebin, "História e narração em Walter Benjamin”, p.11
} 
e não fora dele. Esta questão fortalece ainda mais a ideia de mônada, onde a totalidade, inclusive sua temporalidade, já se encontra no próprio objeto de estudo. Os fatos históricos aparecem isolados e, para serem salvos, devem formar uma constelação, estabelecendo novas ligações entre o passado e o presente. A origem é o momento da salvação, é a salvação do fato que caracteriza sua origem, salvação, aliás, que é o objetivo da filosofia. Ao ser salvo, o fato histórico passa a fazer parte da ordem das ideias. O papel da linguagem é o de mediação salvadora do momento histórico na eternidade das ideias, é o papel de criar a origem instaurando outra temporalidade.

(...) para serem salvos, os fenômenos devem ser arrancados - pelo conceito - a uma falsa continuidade, aquela que é abusivamente chamada objetiva, como se a cronologia não fosse, ela também, o fruto de uma construção historiográfica. ${ }^{17}$

A construção de uma historiografia linear, diz Benjamin nas "Teses", interessa a uma classe dominante que pretende com esta narração coerente instaurar um determinismo na história. A quebra deste determinismo só pode se dar pela instauração de uma nova temporalidade que faça com que o acontecimento histórico pare o tempo e o torne intensivo. Esta temporalidade é atingida com o conceito de origem. A linguagem alegórica aparece como a melhor maneira de apresentar a verdade e a ideia, pois a alegoria, ao abarcar várias interpretações, foge ao sentido congelado da linguagem literal. A alegoria possui uma historicidade que se dá em cada nova interpretação. A verdade se dá nos múltiplos sentidos da alegoria e não no sentido estrito e fechado da escrita sistemática e simbólica. O que se faz com a escrita alegórica é buscar na frase singular uma característica de totalidade. Encontrar na alegoria a verdade que ela apresenta. A alegoria como linguagem capaz de romper com a temporalidade homogênea e fazer aparecer sempre uma nova origem. "A verdade da interpretação alegórica consiste neste movimento de fragmentação e de desestruturação da enganosa totalidade histórica;", ${ }^{18}$.

A temporalidade moderna escorrida, que tem no progresso seu grande valor, é a temporalidade burguesa da história que nos apresenta um homem que ainda hoje não é capaz de se redimir de seu próprio passado. Esta realidade que Benjamin critica e quer

\footnotetext{
${ }^{17}$ Ibidem, p. 16 e 17

${ }^{18}$ Ibidem, p. 43
} 
transformar é uma realidade histórica sombria, que paira sobre a modernidade como uma nuvem carregada pronta para descarregar de novo sua tempestade a qualquer momento. Uma história da qual, ao invés de se orgulhar, o homem moderno dela se envergonha, é uma história triste e que ainda não foi, mas precisa ser redimida. Somente quando o homem for capaz de citar sua história, em cada um de seus momentos, ele estará redimido e salvo. A temporalidade burguesa não permite esta redenção, pois impele o homem, com uma força violenta, para o futuro em nome do progresso. O preço que a humanidade paga por este progresso tecnológico é o preço de não poder falar de sua história. Ao não falar dela, esconde-se também todas as calamidades e holocaustos já realizados em nome deste mesmo progresso. Desta forma segue-se a cronologia do tempo linear que nos força a andar para frente, em nome do progresso, sem que possamos parar e examinar um pouco melhor esta história que continua a ser construída a cada momento. As calamidades cometidas perdemse assim no esquecimento e o conformismo pode reinar. A tarefa do historiador materialista é justamente mergulhar nos pormenores da matéria, encontrando aí sua verdade, sua totalidade. Ao escrever a história a partir de sua materialidade o historiador salva o acontecimento do esquecimento, conferindo-lhe uma nova interpretação e rompendo desta forma com a temporalidade teleológica, sendo então capaz de propor um novo sentido ao presente. Na compreensão burguesa do tempo, um acontecimento é explicado por fatos anteriores e exteriores a ele e que o colocam em uma posição em que seria impossível ser diferente. Ao contrário desta postura que leva irremediavelmente ao conformismo, o rompimento com esta temporalidade causal traz a compreensão de que o presente comporta a possibilidade de diversos futuros diferentes. Em um tempo onde o acontecimento histórico pode romper com a causalidade cronológica dos fatos, um novo futuro pode ser pensado. Por isto, para se transformar a realidade que tanto desagrada a Benjamin, a instauração de uma nova temporalidade é fundamental.

É interessante notar que a escrita histórica proposta por Benjamin pretende romper com a ordem temporal da modernidade, que se caracteriza pela alta velocidade com que algo moderno torna-se obsoleto. Quase ao nascer, o moderno já se torna o seu oposto, o velho. Esta temporalidade acelerada é a temporalidade do progresso onde a tradição se perde. A tradição hoje é a própria passagem, a própria velocidade com que a experiência se perde no tempo. Esta aceleração do tempo dificulta o trabalho do historiador que é bombardeado por 
inúmeros fatos diários e não pode dispor de tempo para pensá-los. Esta temporalidade é inseparável da produção capitalista, que visa sempre à produção de novidades e avanços tecnológicos, mas que, por trás destes avanços esconde uma história triste de se ler. O tempo, que corre em direção a um progresso cada vez mais sem sentido, caracteriza uma modernidade perdida e que a história materialista quer redimir. É justamente na interrupção deste tempo escorrido moderno que se instaura a proposta revolucionária de Benjamin. A interrupção desta história cronológica possibilita outras interpretações dos acontecimentos. Uma parada necessária no tempo para podermos juntar os cacos de nossa história e recompor, a partir daí, um mundo há muito perdido e que pede uma rememoração. A redenção messiânica da humanidade pode se dar em sua história. Contra o tempo que traz consigo o conceito embotado de causalidade histórica, que insere cada acontecimento em uma cadeia que o prende ao passado, a proposta é afirmar a possibilidade de que algo novo aconteça. Em uma cadeia causal de fatos, a história torna-se teleologia e não há nunca novidade. A salvação, a redenção, a revolução, como novidades, só são possíveis com a quebra desta cadeia causal. A afirmação de que algo novo que foge à explicação pode ocorrer, é a afirmação de uma nova temporalidade, de um tempo-agora, de um tempo intensivo. $\mathrm{O}$ instante imobiliza o andamento temporal. A história escrita do presente para o presente imobiliza o passado, suspendendo a cronologia. Esta suspensão é o momento da origem, momento de parada e de criação. A interrupção do tempo cronológico aparece como resistência política a um mundo que se assemelha a um trem em alta velocidade, que corre lotado, com as portas abertas e não pára para socorrer os que caem. Parar o tempo é parar o trem e atender os feridos é olhar a história. Da interrupção pode nascer o novo. Não se trata de oferecer outra explicação "mais correta" para os fatos ocorridos, trata-se de criar um abalo na explicação tradicional e assim, abrir espaço para um novo tempo, introduzir rupturas na história dos vencedores pela dinâmica da origem, que retoma redentoramente o passado pelo e no presente. A lembrança do passado aparece pela necessidade de transformação do presente. Esta prática implica justamente na suspensão de uma historiografia causal e aí, nesta interrupção, a história pode mostrar sua significação salvadora para o presente, uma narração messiânica que cura. 


\section{Referências Bibliografias}

BENJAMIN, Walter. "Sobre a linguagem em geral e sobre a linguagem humana" in Sobre Arte, Técnica, Linguagem e Política. Lisboa. Relógio d`Àgua.1992.

“Questões introdutórias de crítica do conhecimento", in A origem do

drama barroco alemão.

. "Sobre o conceito de história", em: Obras escolhidas. v. I, 4. ed. São

Paulo: Brasiliense, 1985.

GAGNEBIN, Jeanne Marie. "Nas fontes paradoxais da crítica literária. Walter Benjamin relê os românticos de Iena”. em: Leituras de Walter Benjamin, São Paulo: Annablume/ Fapesp, 1999.

Walter Benjamin. Brasiliense, 2.ed. São Paulo: 1993.

História e narração em Walter Benjamin. 2 ed., São Paulo:

Perspectivas, 1999.

- "Do conceito de Darstellung em Walter Benjamim ou verdade e beleza", em Revista Kriterion, Revista da Faculdade de Filosofia da Universidade de Minas Gerais, vol 46, no. 112.

Endereço eletrônico:

http://www.scielo.br/scielo.php?script=sci_arttext\&pid=S0100-512X2005000200004

MURICY, Kátia. “O ser das ideias” in: Alegorias da dialética. Relume Dumará, 1999. 